Check for updates

Cite this: J. Mater. Chem. B, 2020, 8, 5694

\section{Controllable synthesis of biomimetic nano/submicro-fibrous tubes for potential small-diameter vascular grafts $\dagger$}

\author{
Yizao Wan, (D) ab Shanshan Yang, ${ }^{a}$ Mengxia Peng, ${ }^{a}$ Miguel Gama, ${ }^{c}$ Zhiwei Yang, (D) \\ Xiaoyan Deng, ${ }^{\text {ad }}$ Jianye Zhou, (D) Chenxi Ouyang ${ }^{f}$ and Honglin Luo (D) *ab
}

\begin{abstract}
Mimicking the morphological structure of native blood vessels is critical for the development of vascular grafts. Herein, small-diameter composite vascular grafts that integrate the nanofibrous bacterial cellulose (BC) and submicrofibrous cellulose acetate (CA) were fabricated via a combined electrospinning and step-by-step in situ biosynthesis. Scanning electron microscopy (SEM) observation shows the nano/ submicro-fibrous morphology and well-interconnected porous structure of the BC/CA grafts. It is found that the $\mathrm{BC} / \mathrm{CA}$ graft with a suitable $\mathrm{BC}$ content demonstrates lower potential of thrombus formation and enhanced endothelialization as compared to the $B C$ and $C A$ counterparts. Western blotting and $\mathrm{RT}-\mathrm{qPCR}$ results suggest that the $\mathrm{BC} / \mathrm{CA}-2$ graft promotes endothelialization by improving expressions of genes VWF-1 and CD31 and protein CD31. The in vivo tests demonstrate much lower inflammatory response to the $\mathrm{BC} / \mathrm{CA}$ graft. These results suggest that the $\mathrm{BC} / \mathrm{CA}$ graft shows a great potential as an artificial graft for rapid formation of an endothelial cell monolayer.
\end{abstract}

Received 17th April 2020,

Accepted 31st May 2020

DOI: $10.1039 / d 0 t b 01002 b$

rsc.li/materials-b surface modification and controlled drug release approaches. ${ }^{7-9}$ Despite these achievements, the performance of the reported small-diameter vascular grafts is still unsatisfactory. Accordingly, new strategies are highly demanded to develop novel smalldiameter grafts with rapid endothelialization and therefore non-thrombotic. ${ }^{10}$

Recently, mimicking the morphological structures of native tissues becomes a popular strategy. Native blood vessels are composed of three layered structures, i.e., tunica intima, tunica media, and tunica adventitia. ${ }^{11,12}$ of these three layers, replicating the structure of tunica intima is the focus of research on vascular grafts, which contains a monolayer of endothelial cells attached to their basement membrane, and is critical to anti-thrombosis. ${ }^{3,6}$ The basement membrane in tunica intima is composed of a topographically rich three-dimensional (3D) non-woven porous fibrous network in which the fibers are on the nano (1-100 nm) and submicron (100-1000 nm) size scale. The intrinsic topography of the basement membrane plays a critical role in adjusting the adhesion, migration, proliferation, and differentiation of the overlying endothelial cells. ${ }^{13}$ Although a great deal of research has been emphasized on the fabrication of nano/micro-fibrous ${ }^{14,15}$ and nano/submicro-fibrous ${ }^{16,17}$ scaffolds, nano/submicro-fibrous vascular grafts have not yet been reported. Furthermore, many studies focused on the fabrication of structurally biomimetic vascular grafts including bi-layered structures ${ }^{10,18}$ and tri-layered grafts. ${ }^{11}$ The replication of the nano/submicro-fibrous structure of the tunica intima has not 
been reported, partially because it is difficult to integrate nanofibers and submicrofibers within a hollow tube by available techniques.

Herein, bacterial cellulose (BC) was used as the nanofibrous component due to its intrinsic nano-scale fiber diameter (20-100 nm) and great potential as vascular grafts. ${ }^{19-25}$ To this end, we combined BC nanofibers with electrospun submicrofibers of cellulose acetate (CA) to produce tubular grafts using an in-house setup. The main objectives of this work are thus to prepare the nano/submicro-fibrous vascular grafts with varying contents of BC, to evaluate their morphologies, chemical and mechanical properties, in vitro and in vivo biocompatibility, the propensity of the material for endothelialization, and to understand how endothelial cells respond to the nano-submicro-fibrous matrix.

\section{Experimental procedure}

\section{Materials}

The materials for BC biosynthesis including yeast extract, tryptone, disodium phosphate $\left(\mathrm{Na}_{2} \mathrm{HPO}_{4}\right)$, and acetic acid were provided by Beijing Innochem Science \& Technology Co., Ltd, China. All other materials and reagents were purchased from Tianjin Kemiou Chemical Reagent Co., Ltd, Tianjin, China, unless otherwise indicated and used as received without any further purification. The bacterial strain, Komagataeibacter xylinus $\mathrm{X}-2$, was received from Tianjin University of Science and Technology, Tianjin, China.

\section{Preparation of electrospun CA submicrofibrous graft}

Cellulose acetate $\left(\mathrm{CA}, \mathrm{MW}=4.0 \times 10^{4}\right)$ was dissolved into a mixture of acetone/acetic acid ( $1 / 1$ by volume) under constant stirring, resulting in a CA solution with a concentration of $15 \mathrm{wt} \%$. The CA solution was poured into a $10 \mathrm{~mL}$ plastic syringe and fed by a pump through a stainless steel needle. The electrospinning was performed at a voltage of $10 \mathrm{kV}$, a solution flow rate of $5 \mathrm{~mL} \mathrm{~h}^{-1}$, and a throw distance (between collector and needle) of $15 \mathrm{~cm}$ (at approximately $25-30{ }^{\circ} \mathrm{C}$ ) and $40 \%$ relative humidity. The fibers were directly collected on a cylinder rotating at $100 \mathrm{rpm}$ (Fig. 1A) with a diameter corresponding to

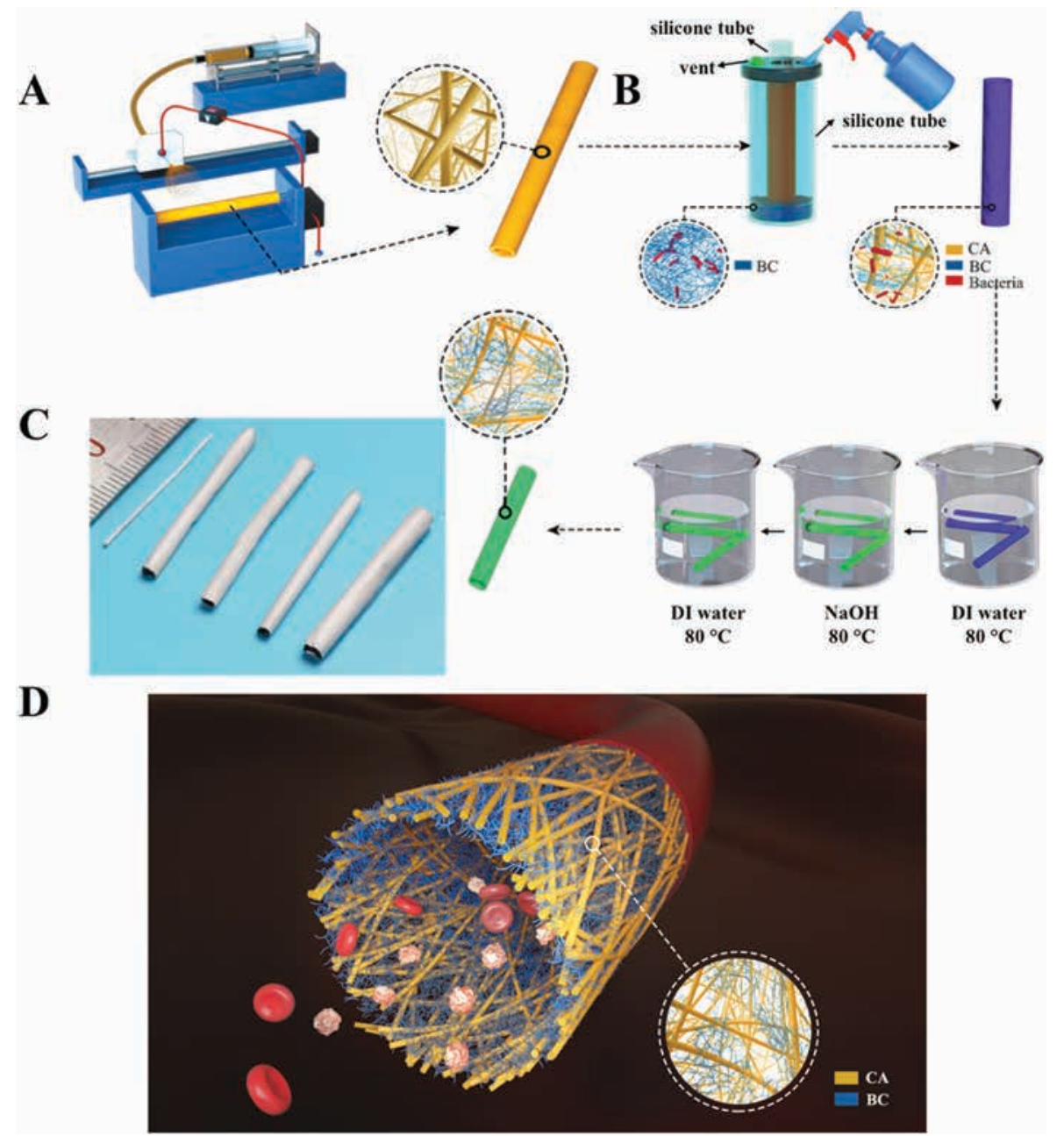

Fig. 1 Preparation of nano/submicro-fibrous BC/CA tubular grafts. (A) Electrospinning was used to generate a tubular submicrofibrous scaffold on top of a rotating cylinder. (B) BC nanofibers in situ grew into the pores within the tubular CA scaffold that serves as a template. (C) The nano/submicro-fibrous hydrogels were cleaned, yielding nano/submicro-fibrous tubular grafts with different diameters. (D) A schematic diagram illustrating the morphological structure of the nano/submicro-fibrous tubular grafts. 
that of the envisaged graft. The obtained submicrofibrous CA graft was vacuum dried at $70{ }^{\circ} \mathrm{C}$ for $24 \mathrm{~h}$ and finally sterilized at $115{ }^{\circ} \mathrm{C}$ for $30 \mathrm{~min}$.

\section{Preparation of nano/submicro-fibrous BC/CA grafts}

The bacterial strain, Komagataeibacter xylinus X-2 was used for the production of $\mathrm{BC}$, and the culture medium $(\mathrm{pH}=4.5)$ for the fermentation consisted of $2.5 \%(\mathrm{w} / \mathrm{v})$ glucose, $0.75 \%(\mathrm{w} / \mathrm{v})$ yeast extract, $1 \%(\mathrm{w} / \mathrm{v})$ tryptone, and $1 \%(\mathrm{w} / \mathrm{v}) \mathrm{Na}_{2} \mathrm{HPO}_{4}$. As illustrated in Fig. 1B, two silicon tubes with different diameters were fixed in the assembly, and the space between them was filled with the culture medium (150-200 $\mu \mathrm{L})$ inoculated with the bacteria. There was sufficient oxygen due to the existence of the vent hole and the silicon tubes. A BC ring (BC substrate) with a thickness of about $2 \mathrm{~mm}$ could be obtained after culture for 1-2 days within the space, which was used as the substrate for the preparation of BC/CA grafts via the step-by-step in situ biosynthesis as reported in our previous studies. ${ }^{26}$ Typically, a tubular CA scaffold $30 \mathrm{~mm}$ long was cut and placed on the top of the BC substrate. The culture medium $(50 \mu \mathrm{L})$ was sprayed to the space between silicon tubes, thus filling the pores of the CA scaffold. After in situ growth of BC within the CA scaffold for $1 \mathrm{~h}$, a second cycle of feeding and growth continued. The process was completed after the 4th cycle, yielding the BC/CA-1 hydrogel. Similarly, BC/CA-2, BC/CA-3, and BC/CA-4 hydrogels were produced, corresponding to 6,8 , and 10 cycles, respectively. The same procedure was employed to produce a bare BC graft for control. Afterward, the BC/CA hydrogels were taken out and purified using the same procedures reported in our previous work, ${ }^{27}$ leading to BC/CA grafts with varying diameters (Fig. 1C). The diameter and thickness of the $\mathrm{BC} / \mathrm{CA}$ grafts were determined by the diameter of the two silicon tubes and the space between them. The morphological structure of the BC/CA grafts is illustrated in Fig. 1D. BC and $\mathrm{BC} / \mathrm{CA}$ grafts were immersed in tertiary butanol for $10 \mathrm{~h}$, renewed every $2 \mathrm{~h}$, followed by washing with deionized water at least three times, for further characterization. The grafts were stored in a freezer at $-20{ }^{\circ} \mathrm{C}$ for $24 \mathrm{~h}$ and finally lyophilized at $-50{ }^{\circ} \mathrm{C}$ for $36 \mathrm{~h}$ to obtain the $\mathrm{BC}$ and $\mathrm{BC} / \mathrm{CA}$ aerogels.

\section{Characterizations}

The digital photographs were taken with a Canon DS126431 digital camera. The morphologies of BC, CA, and BC/CA grafts (in aerogels) were observed with a scanning electron microscope (SEM SU8010, Hitachi, Japan). The fiber diameter was determined by measuring at least 100 randomly selected fiber segments from SEM images using the Nano Measurer 1.2 software, as reported in our previous work. ${ }^{26,28}$ To determine the crystalline structure of graft materials, X-ray diffraction (XRD) analysis was carried out with a Rigaku D/max 2500 $\mathrm{X}$-ray diffractometer using $\mathrm{Cu} \mathrm{K} \alpha$ radiation $(\lambda=0.154 \mathrm{~nm}$; Shimadzu, Japan). The samples were scanned from $10^{\circ}$ to $40^{\circ}$ at a scan speed of $0.02^{\circ} \mathrm{s}^{-1}$. The morphologies were also observed with atomic force microscopy (AFM) using a NT-MDT Ntegra Prima scanning probe microscope operating in the contact mode (Ntegra Prima KFM, NT-MDT, Russia). Thermogravimetric analysis (TGA) was conducted using a Diamond
TG/DTA machine (DTG-60AH, Shimadzu, Japan) by heating 10-15 mg of samples from $30{ }^{\circ} \mathrm{C}$ to $600{ }^{\circ} \mathrm{C}$ at $20{ }^{\circ} \mathrm{C} \mathrm{min}{ }^{-1}$

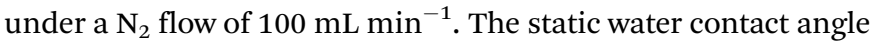
was measured using a Drop Master 300, to characterize the hydrophilicity of the grafts (after pressing at room temperature). Tensile test was conducted using a micro-electromagnetic fatigue testing machine (MUF-1050, Tianjin Care Measure \& Control Co., Ltd, Tianjin, China) with rectangular samples $\left(10 \times 5 \times 2 \mathrm{~mm}^{3}\right)$ at a strain rate of $5 \mathrm{~mm} \mathrm{~min}^{-1}$. The contents of $\mathrm{BC}$ in BC/CA grafts were determined by weighing the dry weight of the $\mathrm{CA}$ and $\mathrm{BC} / \mathrm{CA}$ samples using an electronic balance.

\section{Platelet adhesion}

Fresh platelet rich plasma (PRP) was obtained from rabbits. The blood was centrifuged at $1500 \mathrm{rpm}$ for $15 \mathrm{~min}$ to obtain PRP supernatant. The BC, CA, and BC/CA samples were cut into circular specimens with a diameter of $15 \mathrm{~mm}$ and placed into 24-well culture plates. $100 \mu \mathrm{L}$ of PRP was carefully deposited on each specimen followed by incubation at $37{ }^{\circ} \mathrm{C}$ for $1 \mathrm{~h}$. After washing with PBS solution, these treated specimens were fixed using $0.25 \%$ glutaraldehyde solution for $24 \mathrm{~h}$ and then dehydrated with a series of ethanol solutions (30, 50, 75, 90, $100 \%$ ) for 15 min each. Finally, the dehydrated specimens were air-dried and sputter-coated for SEM observation.

The platelet adhesion on BC, CA, and BC/CA grafts was also quantified by a lactic acid dehydrogenase (LDH) release assay. In brief, fresh PRP $(300 \mu \mathrm{L})$ was dropped on BC, CA, and BC/CA grafts, respectively, and incubated at $37{ }^{\circ} \mathrm{C}$ for $2 \mathrm{~h}$. The PRP suspension was removed from samples, followed by washing with PBS for three times. The lysis solution $(150 \mu \mathrm{L})$ was then dropped on the grafts and incubated at $37{ }^{\circ} \mathrm{C}$ for $1 \mathrm{~h}$ to induce lysis of the adhered platelets and $\mathrm{LDH}$ release. The lysate $(120 \mu \mathrm{L})$ was collected and mixed with the substrate solution $(80 \mu \mathrm{L})$. Finally, the mixtures were centrifuged at $4000 \mathrm{rpm}$ for $5 \mathrm{~min}$ and the supernatants were collected and measured at $490 \mathrm{~nm}$ using a microplate reader (2000, Thermo Fisher, Waltham, USA).

\section{Hemolysis rate determination}

The hemolysis rate was tested using healthy rabbit blood, which was diluted with phosphate buffer saline (PBS) solution with a volume ratio of $4 / 5$ (rabbit blood/PBS). Each circular sample with a diameter of $10 \mathrm{~mm}$ was put into a tube containing $10 \mathrm{~mL}$ of $0.9 \%(\mathrm{w} / \mathrm{v})$ sodium chloride solution and conditioned at $37{ }^{\circ} \mathrm{C}$ for $30 \mathrm{~min}$. Afterward, $0.2 \mathrm{~mL}$ of the diluted blood was added followed by incubation at $37{ }^{\circ} \mathrm{C}$ for $1 \mathrm{~h}$. Finally, the solutions were centrifuged at $3000 \mathrm{rpm}$ for $5 \mathrm{~min}$ and the supernatant was measured at $540 \mathrm{~nm}$ using the aforementioned microplate reader to determine the optical density (OD). The hemolysis rate was calculated using eqn (1). ${ }^{29}$

$$
R=(A-C 1) /(C 2-C 1) \times 100 \%
$$

where $R$ was the hemolysis ratio (\%), $A$ was the absorbance (\%), $C 1$ and $C 2$ were the absorbance of the negative and positive controls (\%), respectively. 


\section{In vitro biocompatibility}

The cell proliferation was evaluated by Cell Counting Kit-8 (CCK-8) assay using human umbilical vein endothelial cells (HUVEC, Shanghai Ninth People's Hospital). The HUVEC cells were cultured in endothelial cell medium (ENCM) supplemented with $10 \%$ fetal bovine serum (FBS) and 1\% ECGS in a humidified incubator with $5 \% \mathrm{CO}_{2}$ at $37{ }^{\circ} \mathrm{C}$. The culture medium was renewed every other day. The circular grafts with a thickness of $1 \mathrm{~mm}$ and a diameter of $14 \mathrm{~mm}$ were sterilized at $121{ }^{\circ} \mathrm{C}$ for 30 min (LDZX-30KBS, Shenan, Shanghai, China). Prior to cell seeding, grafts were immersed in medium with $10 \%$ FBS at $37^{\circ} \mathrm{C}$ for at least $3 \mathrm{~h}$. Afterward, cells were seeded on the grafts with a density of $1 \times 10^{4}$ per well and incubated at $37{ }^{\circ} \mathrm{C}$ in a $5 \% \mathrm{CO}_{2}$ incubator for 1,4 , and 7 days. After incubation, $200 \mu \mathrm{L}$ of mixed medium containing CCK-8 and ENCM $\left(V_{\mathrm{CCK}-8}: V_{\mathrm{ENCM}}=1: 10\right)$ was added to each well followed by incubation in darkness at $37{ }^{\circ} \mathrm{C}$ for $3 \mathrm{~h}$. The culture medium $(100 \mu \mathrm{L})$ was transferred to 96 -well plates and the absorbance was read at $450 \mathrm{~nm}$ using microplate reader (iMark, Bio Rad, California, USA).

After culture under the aforementioned conditions, the grafts were rinsed with PBS (phosphate buffered saline) twice followed by staining with live staining reagent (Fluorescein diacetate). After further incubation for $30 \mathrm{~min}$, the stained cultures were viewed using a fluorescence microscope (TS2, Nikon, Tokyo, Japan).

The cell morphology was observed by SEM. After incubation for 4 and 7 days at $37{ }^{\circ} \mathrm{C}$ in a humidified atmosphere containing $5 \% \mathrm{CO}_{2}$, cells were fixed with $2 \%$ glutaraldehyde solution at $4{ }^{\circ} \mathrm{C}$ for $12 \mathrm{~h}$, and dehydrated in a graded series of ethanol $(50,60,70$, $80,90,95$, and $100 \%$ ). The cell samples were coated with a thin layer of gold, and observed under SEM.

\section{Western blotting}

The Western blotting assay was conducted as reported in our previous work. ${ }^{16}$ Briefly, cells were seeded on grafts for 3 days followed by the removal of the culture medium and washing with PBS three times. Trypsin was added to digest the cells on grafts and transferred to epoxy tube followed by centrifugal washing with PBS. Afterward, $100 \mu \mathrm{L}$ of protein lysate containing protease inhibitor (PMSF) was added to lyse the cells on the ice. The total protein concentration in the lysate was measured with BCA kit and adjusted to $1 \mu \mathrm{g} \mu \mathrm{L}^{-1}$ by adding different volumes of $1 \times$ and $5 \times$ loading buffers. Proteins of different molecular weights were separated with SDS-PAGE gel electrophoresis and transferred onto a PVDF membrane. The membrane was treated with 5\% skimmed milk blocking buffer at $37{ }^{\circ} \mathrm{C}$ for $1 \mathrm{~h}$ and then with diluted rabbit-derived CD31 antibody (bs-04689R, Bioss, China) and mouse-derived GAPDH (ABA0036, Abway, China) solution (1:1000) separately overnight at $4{ }^{\circ} \mathrm{C}$. Thereafter, the membrane was washed with TBST (0.01\% Tween-20 in TBS) for three times and 5 min each time, which was then incubated with goat anti-rabbit and goat anti-mouse second antibodies (Jackson, Hartford, USA) for $1 \mathrm{~h}$ at room temperature. The ECL plus Western blotting substrate was used to visualize the protein bands. The pictures were obtained with Tanon Imager (5200, Tianneng Co., Ltd, Shanghai, China) and band intensity was measured with Image $\mathrm{J}$.

\section{Real time qPCR}

RT-qPCR was used to analyze the expressions of von Willebrand Factor 1 (vWF-1), CD31, and GAPDH as a housekeeping gene. The circular-shaped films were placed inside the 24-well tissue culture dish and HUVEC were seeded at $3.0 \times 10^{4}$ cells per well with ECM in 6 well cell culture-plates. After $24 \mathrm{~h}$, the media were changed with ECM supplemented with FBS (10\%) and cultured for another $48 \mathrm{~h}$. Total RNA was obtained from these samples using Eastep ${ }^{\circledR}$ Super Total RNA Extraction kit (Promega, China), and reverse transcribed to cDNA by Hifair ${ }^{\circledR}$ II 1st Strand cDNA Synthesis SuperMix (YEASEN, China). $400 \mathrm{ng}$ of cDNA was used for each PCR reaction with Hieff ${ }^{\mathbb{R}}$ qPCR SYBR Green Master Mix (YEASEN, China) to determine gene expression of (GAPDH: fw. TGGCGGGGAAGTCAGGT rev. CATGTAAACCATGTAGTTGAGGTC, vWF-1: fw. TTCCCGACAA GGTGTGTGTC rev. TCGCCTTCATGCAGAACGTA, CD31: fw. ACGTGCAGTACACGGAAGTT rev. GGAGCCTTCCGTTCTAGAGT). After an initial denaturation of the cDNA at $95{ }^{\circ} \mathrm{C}$ for $5 \mathrm{~min}, \mathrm{PCR}$ was performed for 40 cycles. Each cycle consisted of denaturation at $95{ }^{\circ} \mathrm{C}$ for $10 \mathrm{~s}$ and primer annealing and primer extensional for $30 \mathrm{~s}$ at $60{ }^{\circ} \mathrm{C}$. Finally, a $5 \mathrm{~min}$ extension step at $60{ }^{\circ} \mathrm{C}$ was performed. The $2-(\Delta \Delta \mathrm{CT})$ method was applied to calculate relative quantification.

\section{In vivo biocompatibility}

The in vivo biocompatibility was tested by subcutaneous implantation experiments. The animal experiments were conducted in accordance with the ethical guidelines approved by the Animal Use and Care Administrative Advisory Committee of East China Jiaotong University. Twelve healthy Institute of Cancer Research (ICR) rats (8-week-old, male, 20-25 g) were selected and anesthetized with ethyl ether. BC, CA, and BC/CA-2 grafts $(10 \mathrm{~mm} \times 10 \mathrm{~mm})$ were sterilized with ethylene oxide and then subcutaneously implanted into the back of rats. After 1 and 2 weeks, the rats were sacrificed and grafts were taken out, fixed with $4 \%$ paraformaldehyde, embedded with paraffin, and sliced for staining with hematoxylin and eosin (H\&E), Masson's trichrome, and immunohistochemistry, separately.

\section{Statistical analysis}

All experiments were performed independently for at least five times and the results were presented as mean value \pm standard deviation (SD). Statistical analysis was performed using SPSS software (version 20), and a one-way ANOVA with the least-significant difference (LSD) post hoc was used to determine the presence of any significant differences between different sample groups. Statistically significant differences were accepted as $p$-value $<0.05$.

\section{Results}

\section{Morphology and structure}

Although electrospinning is a versatile method, it is difficult to prepare a tubular biomimetic structure combining nano (tenths of $\mathrm{nm}$ )/submicro (hundreds of $\mathrm{nm}$ )-fibers. Therefore, we developed 
A
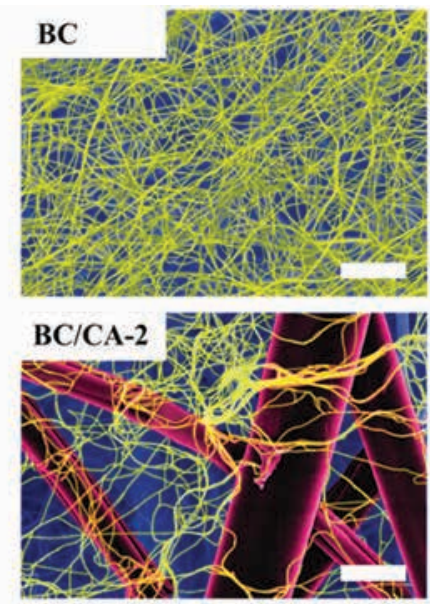

B

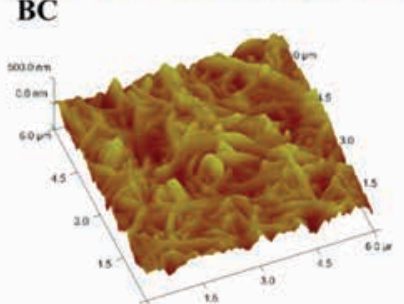

CA
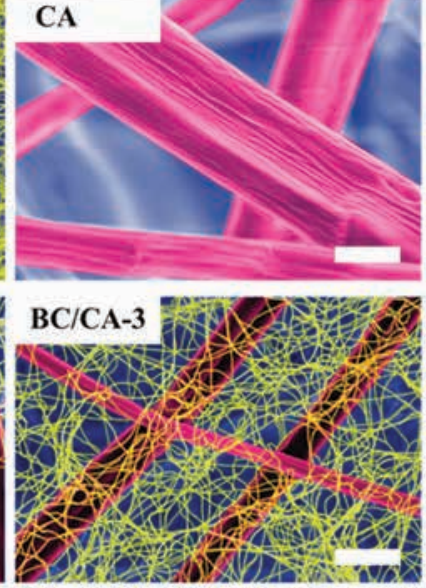

CA

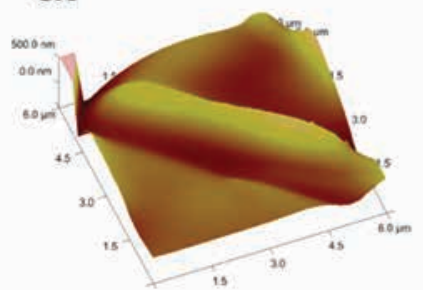

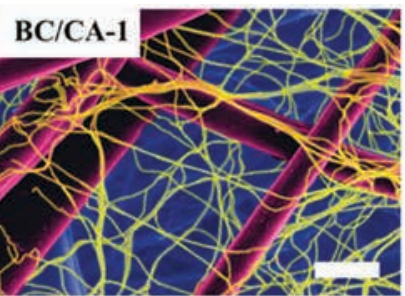

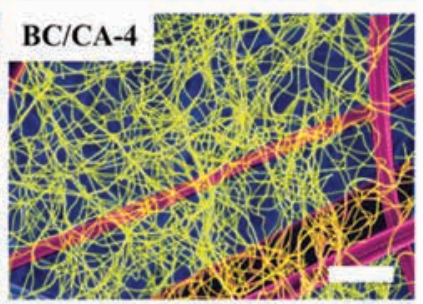

BC/CA-2

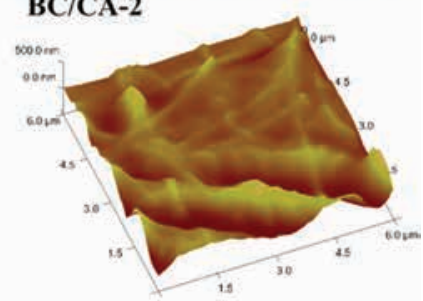

Fig. 2 (A) SEM images of BC, CA, and BC/CA grafts. Scale bar: $2 \mu \mathrm{m}$. (B) AFM images of BC, CA, and BC/CA-2 grafts.

a new fabrication procedure by combining electrospinning and BC fermentation (Fig. 1D). The diameter of the tubular graft can be as small as $1.0 \mathrm{~mm}$ (Fig. 1C). Furthermore, the ratio of $\mathrm{BC}$ nanofibers to CA submicrofibers can be adjusted.

The morphologies of nano/submicro-fibrous grafts were observed by SEM (Fig. 2A) and average fiber diameter was determined (Fig. S1, ESI $\dagger$ ). BC nanofibers with a diameter of about $46-50 \mathrm{~nm}$ and CA submicrofibers with a diameter of 0.64-0.92 $\mu \mathrm{m}$, are combined in an interpenetrated network. Furthermore, $\mathrm{BC}$ nanofibers are present throughout the entire BC/CA grafts, which can be confirmed in Fig. S2 (ESI $\dagger$ ). As shown in Fig. 2A, the number of BC nanofibers increases with the biosynthesis duration (Table S1, ESI $\dagger$ ). The AFM images in Fig. 2B further show details of the combined BC nanofibers/CA submicrofibers network.

XRD analysis was conducted for BC, $\mathrm{CA}$, and $\mathrm{BC} / \mathrm{CA}$ grafts (Fig. 3A). As expected, BC shows three characteristic peaks at $14.6^{\circ}, 16.8^{\circ}$, and $22.8^{\circ}$, which correspond to the (11̄0), (110), and (200) diffraction planes of cellulose, consistent with previous studies. ${ }^{27,30,31}$ The XRD pattern of CA shows a broad peak similar to a previously reported result. ${ }^{32}$ In addition to the peaks assigned to $\mathrm{BC}$, another one at about $20^{\circ}$ is noted in the XRD patterns of $\mathrm{BC} / \mathrm{CA}$ grafts, similar to our previous result. ${ }^{16}$ However, the validation of this peak requires further investigation in the future.

The FTIR spectra of different samples are displayed in Fig. 3B. Characteristic peaks at $3348 \mathrm{~cm}^{-1}, 2890 \mathrm{~cm}^{-1}$, and $1061 \mathrm{~cm}^{-1}$ are observed in the spectrum of $\mathrm{BC}$, which correspond to $-\mathrm{OH}$ bonds, asymmetric stretching vibration of $\mathrm{C}-\mathrm{H}$, and anti-symmetric bridge stretching of $\mathrm{C}-\mathrm{O}-\mathrm{C}$, respectively. ${ }^{33}$ In the FTIR spectrum of CA, $\mathrm{O}-\mathrm{H}$ stretching at $3491 \mathrm{~cm}^{-1},-\mathrm{CH}_{2}$ asymmetric stretching at $2894 \mathrm{~cm}^{-1}$, C-O-C stretching at $1052 \mathrm{~cm}^{-1}$ are noted. ${ }^{34,35}$ The FTIR spectrum of CA also shows $\mathrm{O}-\mathrm{H}$ stretching at $3491 \mathrm{~cm}^{-1},-\mathrm{CH}_{2}$ asymmetric stretching at $2894 \mathrm{~cm}^{-1}$, and $\mathrm{C}-\mathrm{O}-\mathrm{C}$ stretching at $1052 \mathrm{~cm}^{-1} \cdot{ }^{34,35}$ These peaks are also seen in the spectra of $\mathrm{BC} / \mathrm{CA}$ materials. Note that the $\mathrm{C}=\mathrm{O}$ in-plane stretching vibration at $1740 \mathrm{~cm}^{-1}$ is also observed in the spectrum of CA, which indicates the formation of ester group as a result of acetylation reaction. ${ }^{36}$ However, this peak is not detected in the spectra of BC/CA materials due to acetate hydrolysis in alkaline medium during purification of BC. ${ }^{35}$ Compared with CA, a significant red shift for $-\mathrm{OH}$ groups is observed in $\mathrm{BC} / \mathrm{CA}$, due to the formation of hydrogen bonding between $\mathrm{BC}$ and $\mathrm{CA}^{26}$

\section{Physical properties}

Thermal stability of $\mathrm{BC}, \mathrm{CA}$, and $\mathrm{BC} / \mathrm{CA}$ materials was determined (Fig. S3, ESI $\dagger$ ). The TGA curves reveal a similar threestage trend-a slight weight loss below $100{ }^{\circ} \mathrm{C}$ due to water evaporation, ${ }^{37}$ a drastic weight loss at $250-400{ }^{\circ} \mathrm{C}$ due to degradation of main cellulose skeleton, ${ }^{38}$ and a stable stage at higher temperatures. Moreover, the TGA result indicates a slight positive effect of $\mathrm{BC}$ on the stability of the $\mathrm{BC} / \mathrm{CA}$ materials.

Wettability is an important factor with great influence on cell attachment. ${ }^{39,40}$ The water contact angles of BC, CA, and $\mathrm{BC} / \mathrm{CA}$ materials were tested and the results are presented in Fig. S4 (ESI $\dagger$ ). CA is hydrophobic with an average contact angle of $121.2^{\circ}$, but $\mathrm{BC}$ is hydrophilic with an average contact angle of $32.1^{\circ}$. The contact angles of the $\mathrm{BC} / \mathrm{CA}$ materials lie between those of the $\mathrm{BC}$ and $\mathrm{CA}$, ranging from $53.3^{\circ}$ to $100.8^{\circ}$.

The tensile stress-strain curves (Fig. 4A) show that the maximum stress and strain at break are different. The quantitative 
A

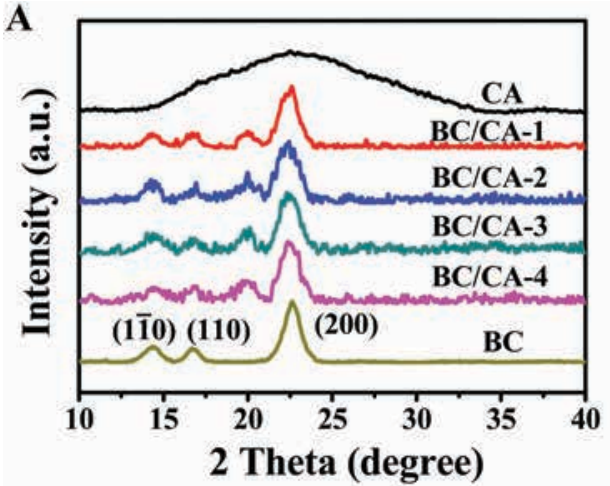

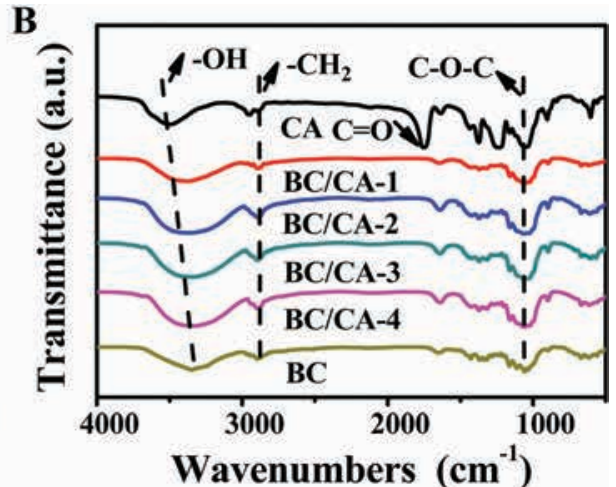

Fig. $3 \times R D(A)$ and $F T I R(B)$ results of $B C, C A$, and $B C / C A$ grafts.

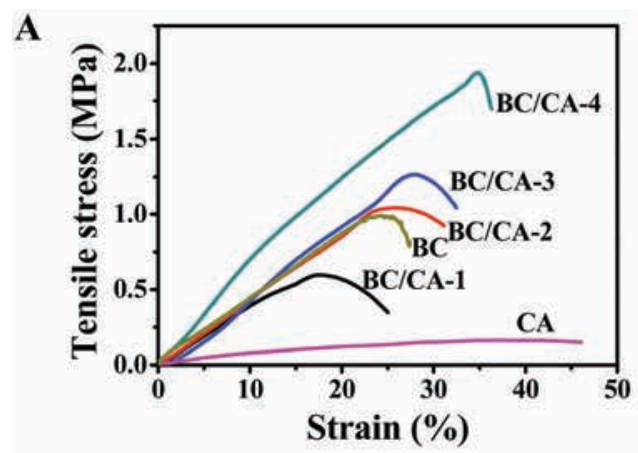

C

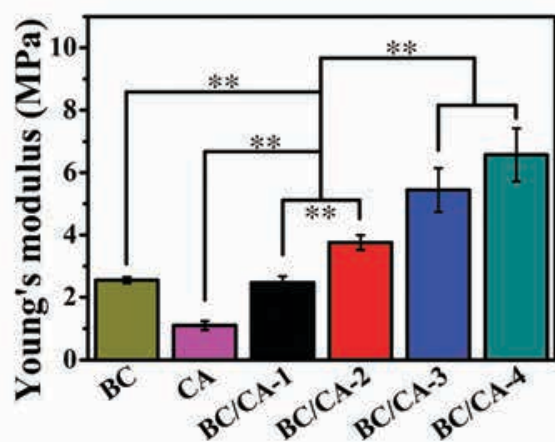

B

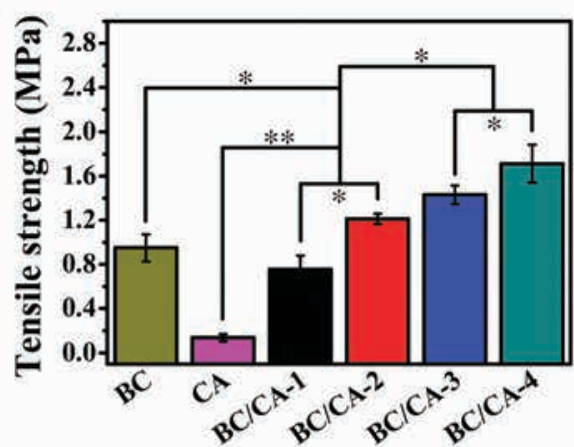

D

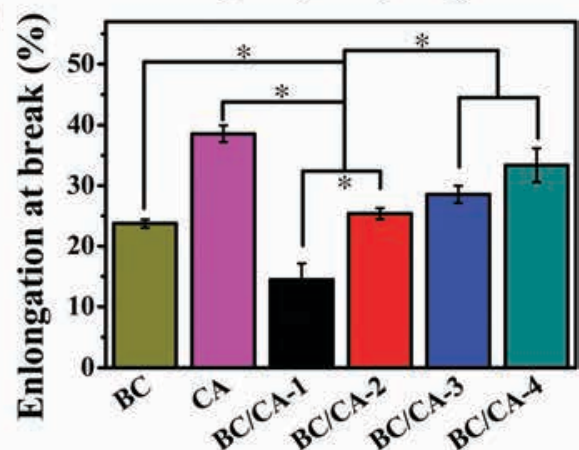

Fig. 4 Mechanical properties of BC, CA, and BC/CA materials: (A) typical stress-strain curves, (B) tensile strength, (C) Young's modulus, (D) strain at break. Statistical significance was defined as ${ }^{*} p<0.05,{ }^{*} p<0.01, n=5$. ns represents not significant, $p>0.05$

results of tensile strength, Young's modulus, and strain at break are shown in Fig. 4B-D. Note that CA shows the lowest tensile strength $(0.14 \pm 0.03 \mathrm{MPa})$ and Young's modulus $(1.09 \pm$ $0.14 \mathrm{MPa})$, but the highest strain at break (38.56 $\pm 1.38 \%)$. BC exhibits a tensile strength of $0.95 \pm 0.12 \mathrm{MPa}$, which is higher than that $(0.38 \pm 0.1 \mathrm{MPa})$ reported by Xie et $a l^{41}$ As shown in Fig. $4 \mathrm{~B}$ and $\mathrm{C}$, adding $\mathrm{BC}$ to CA significantly increases the tensile strength and Young's modulus. Furthermore, BC/CA-2, BC/CA-3, and BC/CA-4 show significantly higher tensile strength, Young's modulus and strain at break compared with $\mathrm{BC}(p<0.05$ for tensile strength and strain, and $p<0.01$ for Young's modulus).

\section{In vitro characterization}

Platelet adhesion and activation on a material's surface may induce thrombosis, and is thus of utmost importance in the assessment of vascular grafts. ${ }^{42,43}$ In this work, SEM images of platelets adhered on $\mathrm{BC}, \mathrm{CA}$, and $\mathrm{BC} / \mathrm{CA}$ surfaces are presented in Fig. 5A. The quantitative results are displayed in Fig. 5B and the scheme showing the locations of platelets on BC/CA grafts is illustrated in Fig. 5C. A large number of platelets adhere on the surfaces of $\mathrm{BC}$ and $\mathrm{BC} / \mathrm{CA}-4$, partially showing irregular morphology, aggregation, and widely spread shape, which may indicate activation and potential for thrombus formation. ${ }^{44,45}$

The number of adherent platelets was quantified via the LDH assay (Fig. 5B). Note that significantly fewer platelets are observed on BC/CA-1 and BC/CA-2 as compared to BC/CA-3 and $\mathrm{BC} / \mathrm{CA}-4(p<0.05)$. There is no significant difference in the number of adhered platelets between BC/CA-1 and BC/CA-2, and a few observed exhibit grainy shape without pseudopodia or deformation (Fig. 5A), indicating that they are not activated. 
A
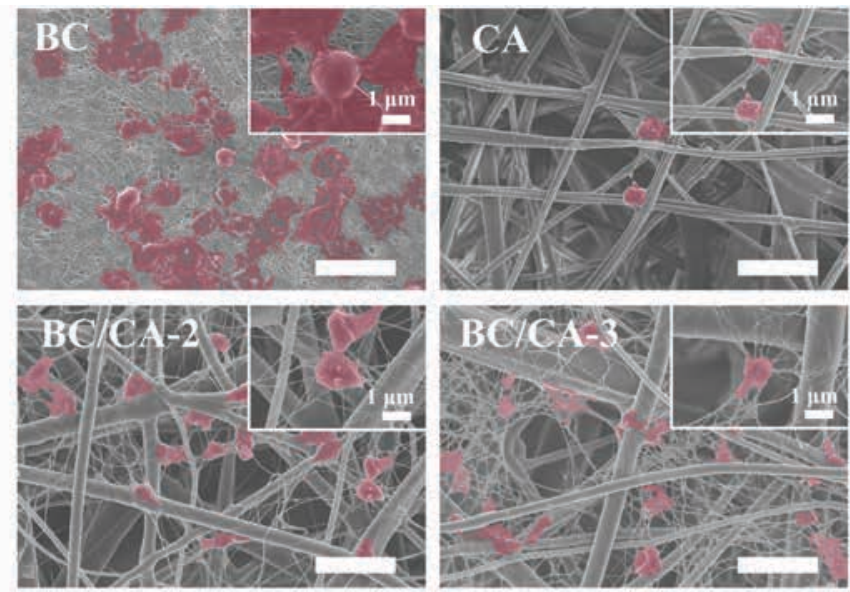

B

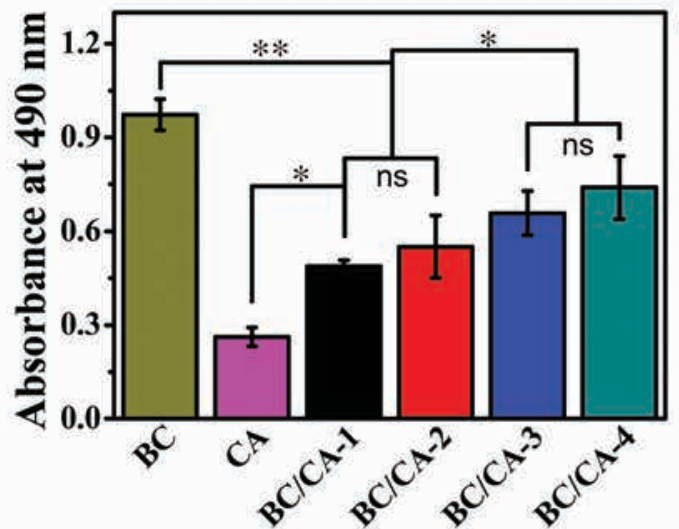

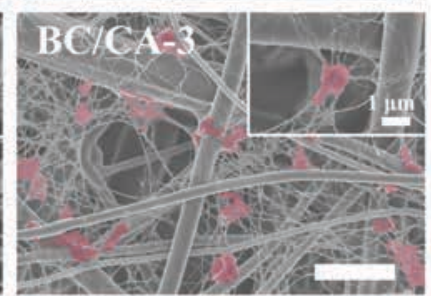

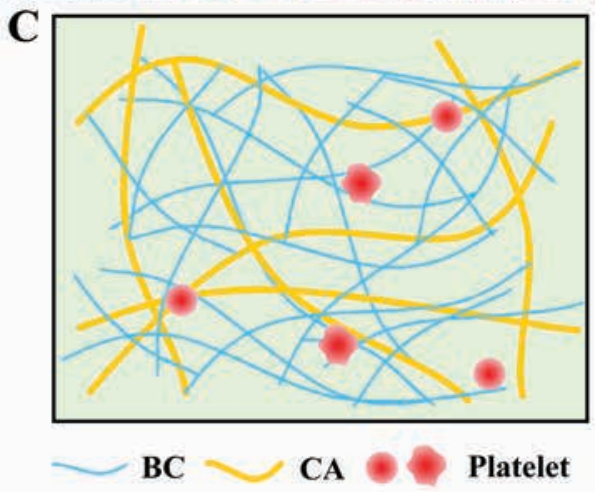

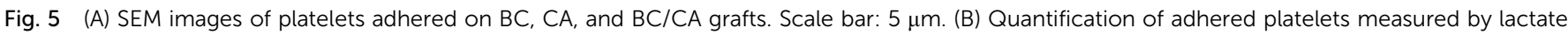

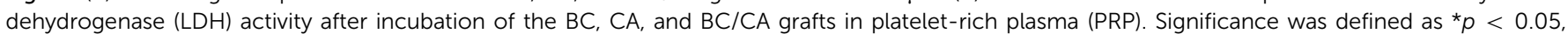
${ }^{\star *} p<0.01, n=5$. ns represents not significant, $p>0.05$. (C) Illustration of platelets on BC/CA grafts.

This result suggests that $\mathrm{BC} / \mathrm{CA}-1$ and $\mathrm{BC} / \mathrm{CA}-2$ grafts have good hemocompatibility and anti-thrombogenic potential.

Blood contacting materials must be non-toxic for blood cells. A high hemolysis rate means a large amount of breakup of cell membranes, which accelerates clotting and thrombus formation. $^{43,46}$ A hemolysis rate below the threshold of $5 \%$ means little harm to red blood cells, ${ }^{47}$ while a value of $0-2 \%$ is classified as non-hemolytic according to the American Society for Testing and Materials. ${ }^{48}$ Note that all BC/CA grafts have lower hemolysis rates than BC, but higher than CA. Moreover, As shown in Table 1, all grafts exhibit a hemolysis rate much lower than $1 \%$. The hemolysis rate of $\mathrm{BC} / \mathrm{CA}-2$ is $0.28 \%$, which is lower than those of the ePTFE vascular graft (0.9\%) reported by Chen et al. $^{49}$ and an electrospun spider silk protein/PCL/ gelatin graft $(0.3 \%)$ reported by Xiang et al. ${ }^{50}$

Table 1 Hemolysis rate of $\mathrm{BC}, \mathrm{CA}$, and $\mathrm{BC} / \mathrm{CA}$ grafts

\begin{tabular}{lll}
\hline Samples & Hemolysis rate $(\%)$ & Standard deviations \\
\hline CA & 0.11 & 0.00057 \\
BC/CA-1 & 0.19 & 0.00078 \\
BC/CA-2 & 0.28 & 0.00084 \\
BC/CA-3 & 0.33 & 0.00067 \\
BC/CA-4 & 0.52 & 0.00111 \\
BC & 0.65 & 0.00218
\end{tabular}

The formation of a complete endothelial layer on the surface of vascular grafts is crucially important to enhance long-term patency. ${ }^{45,51}$ Endothelialization was monitored in vitro by seeding HUVECs onto BC, CA, and BC/CA grafts. The SEM images (Fig. 6A) show increased cell coverage on all grafts when the culture time increases from 4 to 7 days. At day 7 , extensive cell proliferation, spreading, and attachment are observed on BC/CA-1 and BC/CA-2 grafts. Fig. 6B demonstrates quicker endothelialization of $\mathrm{BC} / \mathrm{CA}-1$ and $\mathrm{BC} / \mathrm{CA}-2$ grafts than other grafts.

The CCK-8 assay results further confirm these observations (Fig. 6C). The difference in the cell viability among the grafts is not significant after 1 day culture. At day 4, the proliferation level is significantly higher on BC/CA-1 and BC/CA-2 as compared to other grafts $(p<0.01)$. The same trend remains unchanged at day 7. The biocompatibility was also evaluated by fluorescence staining. Fig. S5 (ESI $\dagger$ ) shows images of HUVEC cells seeded on BC, $\mathrm{CA}$, and BC/CA grafts. The amount of HUVEC cells continuously increases with increase of culture time, suggesting robust proliferation on all grafts.

Taken together, hybridizing nanofibrous BC with submicrofibrous CA can potentially decrease the thrombosis, demonstrating great potential for application in vascular grafts. To further evaluate the performance of $\mathrm{BC} / \mathrm{CA}$ grafts, BC/CA-2 was 
A
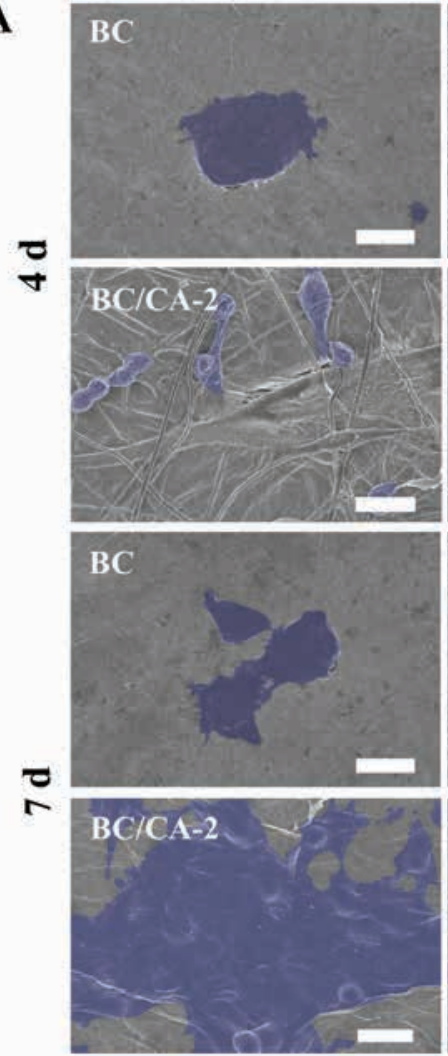
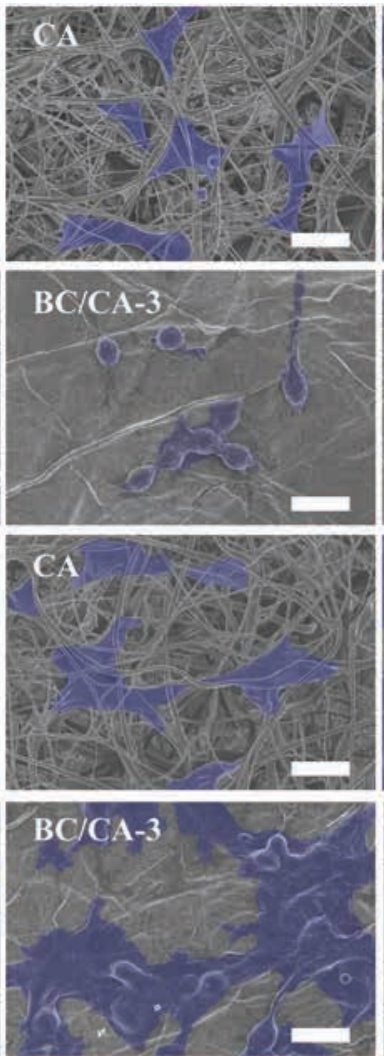
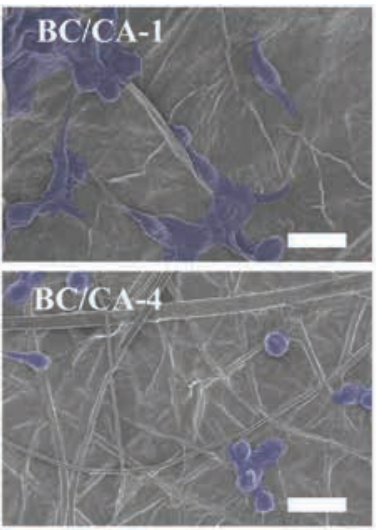

$\mathrm{BC} / \mathrm{CA}-1$
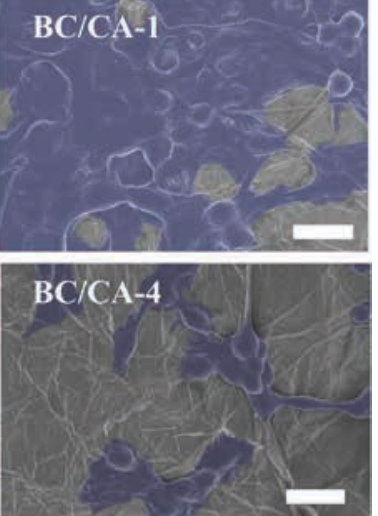

B

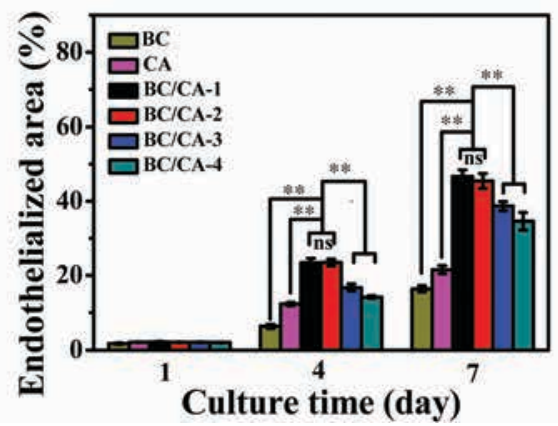

C

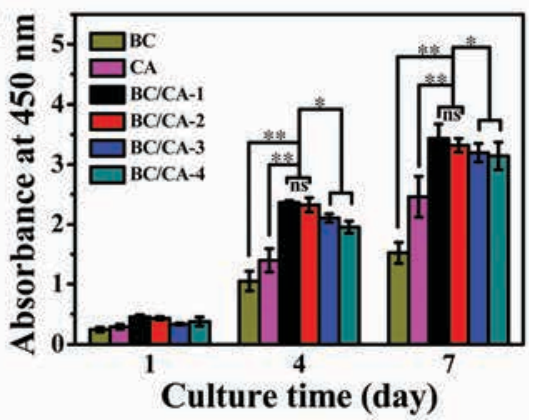

Fig. 6 (A) SEM images of HUVEC cells seeded on BC, CA, and BC/CA grafts for 4 and 7 days. Scale bar: $20 \mu m$. (B) Area of endothelialization counted by the area occupied by HUVEC cells. (C) CCK- 8 assay results. Significance was defined as ${ }^{*} p<0.05,{ }^{* *} p<0.01, n=5$. ns represents not significant, $p>0.05$.

selected for Western blotting assay and in vivo biocompatibility assessment, which exhibits improved mechanical properties than BC/CA-1, and comparable in vitro biocompatibility, hemolysis rate, and platelet adhesion and activation.

To further demonstrate the advantage of BC/CA grafts, the expression of CD31 protein was assessed using the Western blotting assay. The results shown in Fig. 7A and $\mathrm{B}$ reveals the relative expression of $\mathrm{CD} 31(0.82 \pm 0.08)$ on $\mathrm{BC} / \mathrm{CA}-2$ is 1.6 times higher than $\mathrm{BC}(0.50 \pm 0.01)$, and is also significantly higher than CA $(0.72 \pm 0.06, p<0.05)$.

The expressions of the HUVEC-specific markers, genes vWF-1 and CD31, were examined at the mRNA level. As shown in Fig. 7C, the relative expression levels of vWF and CD31 on BC/CA-2 are significantly higher than those on BC and CA $(p<0.01)$.

\section{In vivo biocompatibility evaluation}

In vivo biocompatibility of materials can be evaluated by subcutaneous implantation, which can demonstrate the degree of inflammatory response and foreign body reaction. ${ }^{52}$ In this work, BC, CA, and BC/CA-2 grafts were subcutaneously implanted into rats for up to 2 weeks. The H\&E staining images in Fig. 8A reveal fewer inflammatory cells around the BC/CA-2 graft as compared to BC and CA grafts. The Masson's trichrome staining results (Fig. 8B) demonstrate a thinner fibrotic capsule around $\mathrm{BC} / \mathrm{CA}-2$ graft as compared to $\mathrm{BC}$ and $\mathrm{CA}$ grafts. The results of immunohistochemical DAB staining (Fig. 8C) presents that there are a large number of inflammatory cells of CD8+ in the surrounding tissues of BC and CA grafts, while the BC/CA-2 graft shows much fewer inflammatory cells, indicating less rejection reaction of the $\mathrm{BC} / \mathrm{CA}-2$ graft than $\mathrm{BC}$ and $\mathrm{CA}$ grafts. 
A

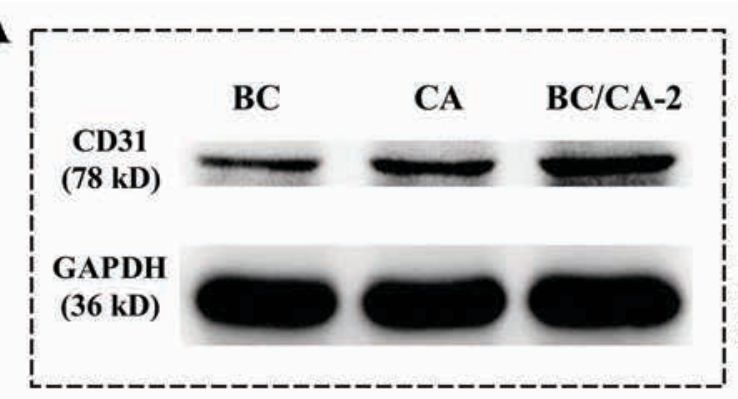

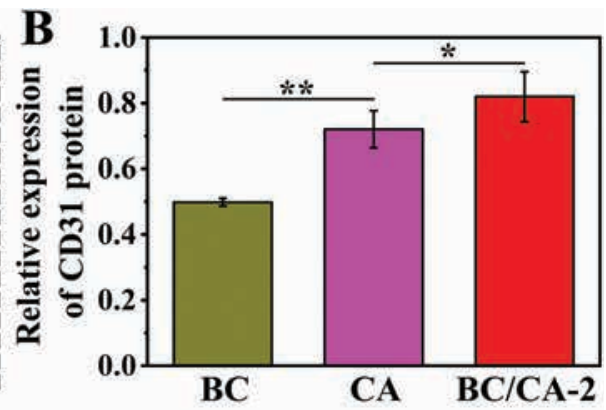

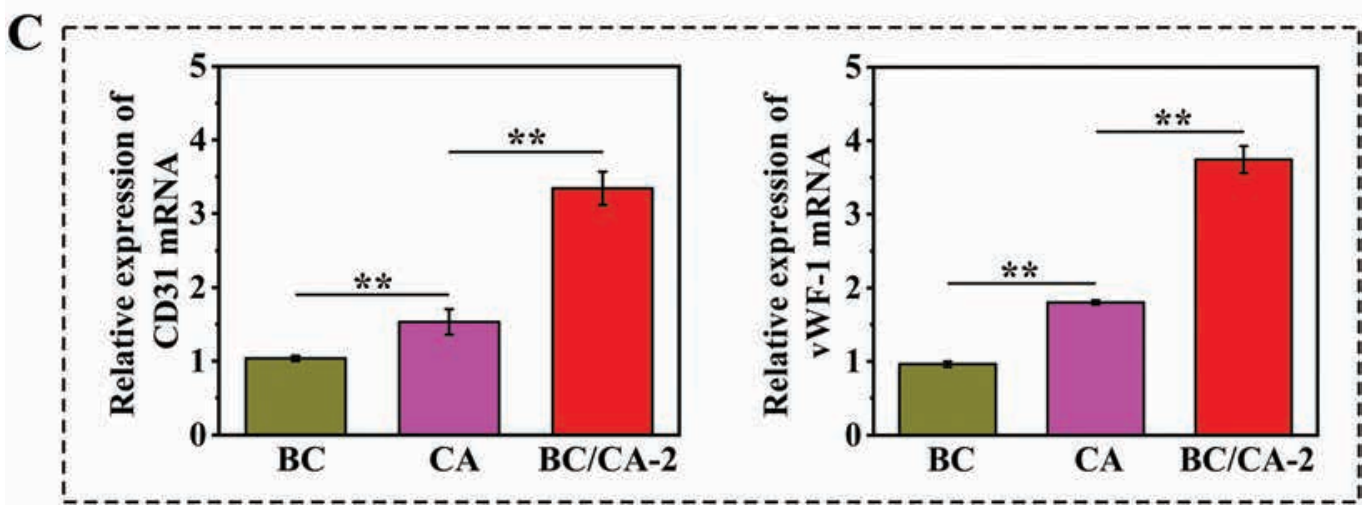

Fig. 7 Western blot $(A)$ and $(B)$ and real-time quantitative PCR (C) after cell culture on BC, CA, and BC/CA-2 for 3 days. (A) Representative images of Western blotting assay. (B) Relative expression of CD31 protein. (C) Relative expression levels of vWF-1 and CD31 genes. Significance was defined as ${ }^{*} p<0.05$ or ${ }^{* *} p<0.01, n=6$ in each group.

These results suggest that the $\mathrm{BC} / \mathrm{CA}-2$ graft has improved in vivo biocompatibility over bare $\mathrm{BC}$ and CA grafts.

\section{Discussion}

An ideal small-diameter vascular graft should mimic the morphology of native blood vessels. Native extracellular matrices (ECMs) mainly consist of collagen fibrils that have a diameter ranging from 50 (nanoscale) to $500 \mathrm{~nm}$ (submicron scale). Such morphology is crucially important for cell adhesion and proliferation. ${ }^{53-56}$ To this end, different techniques such as electrospinning, ${ }^{57,58}$ thermally induced phase separation, ${ }^{59}$ melt spinning, ${ }^{60}$ self-leaching, ${ }^{61}$ and freeze drying, ${ }^{62}$ have been developed to fabricate matrices with biomimetic morphology in recent years. Among these methods, electrospinning is the most widely used. However, it is not easy to fabricate fibers with diameters down to the nanoscale (the lower limit of $50 \mathrm{~nm}$ in natural ECMs). ${ }^{63,64}$ Mimicking the nano/submicro-fibrous morphology of native blood vessels still remains a great challenge. In this study, we developed morphologically biomimetic vascular grafts composed of BC nanofibers and CA submicrofibers using a combined method of electrospinning and step-by-step in situ biosynthesis. We previously prepared nano/submicro-fibrous scaffolds for tissue engineering or cancer cell culture. ${ }^{16,17,65}$ Although the nano/submicro-fibrous structure was mimicked, the $\mathrm{BC} / \mathrm{CA}$ ratio has not been modulated, which might affect the morphology, mechanics and in vitro/in vivo biological behaviors of the $\mathrm{BC} / \mathrm{CA}$ grafts, particularly endothelialization. In this study, we can control the $\mathrm{BC} / \mathrm{CA}$ ratio by adjusting the in situ biosynthesis duration. The result in Table S1 (ESI $\dagger$ ) confirms that the content of BC nanofibers varies from 2.7 to $9.1 \mathrm{wt} \%$ and more importantly it affects the mechanical properties of the BC/CA grafts. All $\mathrm{BC} / \mathrm{CA}$ grafts except for BC/CA-1 exhibit significantly higher tensile strength and Young's modulus compared with bare BC $(p<0.05)$, which, when used alone, has been reported as an appropriate material for vascular graft. ${ }^{19-21,25}$ It is therefore deduced that $\mathrm{BC} / \mathrm{CA}-2, \mathrm{BC} / \mathrm{CA}-3$, and $\mathrm{BC} / \mathrm{CA}-4$ have suitable mechanical properties for vascular grafts.

SEM observation demonstrates that the fiber diameters of BC nanofibers and CA submicrofibers are 46-50 $\mathrm{nm}$ and 0.64$0.92 \mu \mathrm{m}$, respectively, which are comparable to the size range of collagen fibers in native tissues. The diameter of fibers plays an important role in the adhesion of the cells to the fibers. ${ }^{66,67}$ Previous in vitro experiments demonstrated that micron-sized fibrous substrates could support human HUVEC monolayer formation, ${ }^{68}$ while other studies suggested that small-diameter fibers represent a better basis for endothelialization. ${ }^{69-71}$ For instance, Milleret et al. claimed that thin fibers (diameter < $1 \mu \mathrm{m})$ triggered very low coagulation and few adhered platelets while larger fiber diameter $(2-3 \mu \mathrm{m})$ triggered higher thrombosis formation and more adhered platelets. ${ }^{69}$ These findings seemed to indicate that grafts with small fiber diameter could reduce early thrombogenicity due to lower platelet adhesion and activation. However, no report can be found in literature on the use of ultra-thin $(<100 \mathrm{~nm})$ fibrous structure as vascular grafts except for nanofibrous BC. It is noteworthy that although bare BC grafts demonstrated good functions, ${ }^{19-25}$ the combination 


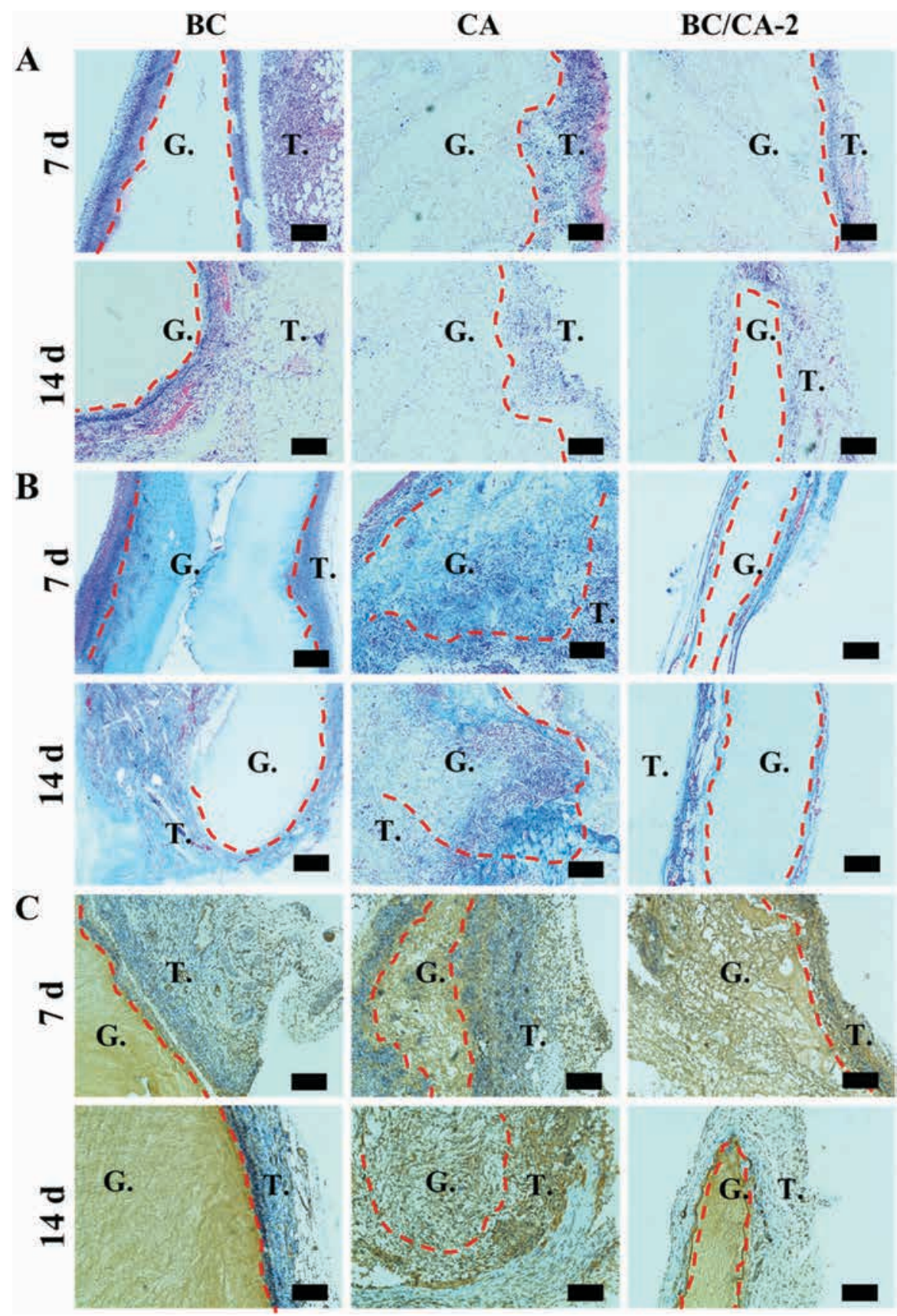

Fig. 8 In vivo results from subcutaneous implantation of BC, CA, and BC/CA-2 grafts in the back of rats for 7 and 14 days. (A) H\&E staining images of samples: the nucleus was dyed blue-black; the color of the components in the cytoplasm and the extracellular matrix were red. (B) Masson's trichrome staining images of samples: collagen fibers and mucus are stained blue; muscle fibers, cellulose, and erythrocytes are stained red; the nucleus was dyed blue-black. (C) DAB staining images of samples: CD8 positive stained brownish yellow; the nucleus was dyed blue-black. G. and T. represent grafts and tissues, respectively. Scale bars: $100 \mu \mathrm{m}$.

of $\mathrm{BC}$ nanofibers with submicrofibers as vascular grafts has not yet been reported.

The activation of platelets is considered to be the first step of thrombogenesis, compromising the patency of vascular grafts. ${ }^{72}$ As displayed in Fig. 5 and Table 1, the BC/CA-2 graft exhibits lower platelet adhesion and hemolysis rate compared with the other grafts, suggesting that improved hemocompatibility may be achieved by optimizing the $\mathrm{BC}$ content.
As shown in Fig. 6A and B, endothelialization of the BC/CA-2 graft quickly occurs. Furthermore, Western blotting and RT-qPCR results (Fig. 7) confirm the enhanced expressions of protein CD31 and genes CD31 and vWF-1 from BC/CA-2 samples as compared to single $\mathrm{BC}$ and $\mathrm{CA}$ samples. CD31 is highly localized in endothelial cell junctions for robust endothelialized structure. ${ }^{73}$ CD31 not only participates in the construction and maintenance of a stable endothelial cell layer, but is also related to 
neo-vascularization and angiogenesis. ${ }^{74}$ It is believed that vWF-1 is a vital predictor of endothelialization after graft implantation in blood vessel. ${ }^{75}$ Therefore, together with the in vitro endothelialization result, the Western blotting and RT-qPCR results suggest that the BC/CA-2 graft can promote endothelialization, and thus reduce formation of thrombosis and increase patency.

Subcutaneous implantation into animals is important for the evaluation of in vivo biocompatibility of materials before in situ implantation. The results in Fig. 8 display lower inflammatory response of $\mathrm{BC} / \mathrm{CA}-2$ as compared to bare $\mathrm{BC}$ and CA. Therefore, both the in vitro (Fig. 6C) and in vivo biocompatibility experiments confirm that the BC/CA-2 possesses excellent biocompatibility, demonstrating great potential to be used as vascular grafts.

The overall excellent performance of BC/CA-2 graft can be explained as follows: (1) chemically, cellulose is believed to be nonthrombogenic with low platelet adhesion and low coagulation activation ${ }^{76}$ and more importantly $\mathrm{BC}$ has been confirmed by many researchers to have great potential for vascular grafts. $^{19-25}$ (2) Mechanically, BC/CA-2 shows a higher tensile strength than bare $\mathrm{BC}$ and is comparable to that of human umbilical vein. $^{77}$ (3) More importantly, morphologically, the size of BC nanofibers is close to that of the lower limit of collagen fibrils $(50 \mathrm{~nm})$ in native tissues and the CA submicrofibers show comparable size to that of the upper limit of native collagen fibrils $(500 \mathrm{~nm})$, which means that the BC/CA-2 possesses biomimetic nano/submicro-fibrous morphology that contributes to cell spreading and cell functions. ${ }^{78,79}$

\section{Conclusions}

The nano/submicro-fibrous BC/CA grafts with biomimetic structure have been fabricated via a combined method of electrospinning and modified in situ biosynthesis. The BC/CA grafts show fibrous and interconnected porous structure with nanofibers (46-50 $\mathrm{nm})$ and submicrofibers $(0.64-0.92 \mu \mathrm{m})$. The mechanical properties of the nano/submicrofibrous BC/CA grafts (except for BC/CA-1) are improved compared with CA and $\mathrm{BC}$ grafts, due to the mechanical entanglement and hydrogen bonding between BC nanofibers and CA submicrofibers. Endothelial cells actively spread with a higher density after seeding on the surface of the $\mathrm{BC} / \mathrm{CA}-2$ graft for 7 days, compared with $\mathrm{BC} / \mathrm{CA}-3$ and $\mathrm{BC} / \mathrm{CA}-4$ grafts, showing promotion of endothelialization by the $\mathrm{BC} / \mathrm{CA}-2$ graft. The platelet adhesion test demonstrates that fewer adhered platelets are observed on the BC/CA-2 graft and the hemolysis assay result displays lower hemolysis rate for the $\mathrm{BC} / \mathrm{CA}-2$ graft, compared with the $\mathrm{BC} / \mathrm{CA}-3$ and $\mathrm{BC} / \mathrm{CA}-4$ grafts. The in vitro $\mathrm{CCK}-8$ assay indicates that the $\mathrm{BC} / \mathrm{CA}-2$ graft has better biocompatibility than the BC/CA-3 and $\mathrm{BC} / \mathrm{CA}-4$ grafts, as well as $\mathrm{BC}$ and CA grafts. Western blotting and RT-qPCR results demonstrate promoted endothelialization of the BC/CA-2 graft by upregulating expressions of genes vWF-1 and $\mathrm{CD} 31$ as well as protein $\mathrm{CD} 31$. In vivo results demonstrate that the BC/CA-2 graft displays significantly better biocompatibility than nanofibrous $\mathrm{BC}$ and submicrofibrous CA grafts. These findings suggest that the $\mathrm{BC} / \mathrm{CA}-2$ graft shows a great potential as a new type of vascular grafts. This study provides a new guideline for the development of biomimetic vascular grafts.

\section{Conflicts of interest}

There are no conflicts to declare.

\section{Acknowledgements}

This work was supported by the National Natural Science Foundation of China (Grant no. 51973058, 31870963, 31760265) and Key Research and Development Program of Jiangxi Province (No. 20192ACB80008).

\section{Notes and references}

1 D. G. Seifu, A. Purnama, K. Mequanint and D. Mantovani, Nat. Rev. Cardiol., 2013, 10, 410-421.

2 W. Wang, D. Liu, D. Li, H. Du, J. Zhang, Z. You, M. Li and C. He, Colloids Surf., B, 2019, 181, 963-972.

3 A. Hasan, A. Memic, N. Annabi, M. Hossain, A. Paul, M. R. Dokmeci, F. Dehghani and A. Khademhosseini, Acta Biomater., 2014, 10, 11-25.

4 S. Ravi, Z. Qu and E. L. Chaikof, Vascular, 2009, 17, 45-54.

5 S. Greenwald and C. Berry, J. Pathol., 2000, 190, 292-299.

6 T. Jungst, I. Pennings, M. Schmitz, A. J. Rosenberg, J. Groll and D. Gawlitta, Adv. Funct. Mater., 2019, 29, 1905987.

7 F. Clauder, A. S. Czerniak, S. Friebe, S. G. Mayr, D. Scheinert and A. G. Beck-Sickinger, Bioconjugate Chem., 2019, 30, 2664-2674.

8 B. Zhang, R. Yao, L. Li, Y. Wang, R. Luo, L. Yang and Y. Wang, ACS Appl. Mater. Interfaces, 2019, 11, 41165-41177.

9 X. Bao, W. Wang, C. Wang, Y. Wang, J. Zhou, Y. Ding, X. Wang and Y. Jin, Biomaterials, 2014, 35, 8450-8466.

10 X. Dong, X. Yuan, L. Wang, J. Liu, A. C. Midgley, Z. Wang, K. Wang, J. Liu, M. Zhu and D. Kong, Biomaterials, 2018, 181, 1-14.

11 H.-Y. Mi, Y. Jiang, X. Jing, E. Enriquez, H. Li, Q. Li and L.-S. Turng, Mater. Sci. Eng., C, 2019, 98, 241-249.

12 F. H. Silver, P. B. Snowhill and D. J. Foran, Ann. Biomed. Eng., 2003, 31, 793-803.

13 J. A. Wood, S. J. Liliensiek, P. Russell, P. F. Nealey and C. J. Murphy, Materials, 2010, 3, 1620-1639.

14 K. Tuzlakoglu, M. I. Santos, N. Neves and R. L. Reis, Tissue Eng., Part A, 2010, 17, 463-473.

15 A. S. Nain, J. A. Phillippi, M. Sitti, J. MacKrell, P. G. Campbell and C. Amon, Small, 2008, 4, 1153-1159.

16 H. Luo, D. Gan, M. Gama, J. Tu, F. Yao, Q. Zhang, H. Ao, Z. Yang, J. Li and Y. Wan, Mater. Sci. Eng., C, 2020, 108, 110416.

17 H. Luo, T. Cui, D. Gan, M. Gama, Q. Zhang and Y. Wan, Polym. Test., 2019, 80, 106107. 
18 S. Park, J. Kim, M.-K. Lee, C. Park, H.-D. Jung, H.-E. Kim and T.-S. Jang, Mater. Des., 2019, 181, 108079.

19 S. E. Lee and Y. S. Park, Mol. Cell. Toxicol., 2017, 13, 257-261.

20 A. F. Leitao, M. A. Faria, A. M. R. Faustino, R. Moreira, P. Mela, L. Loureiro, I. Silva and M. Gama, Macromol. Biosci., 2016, 16, 139-150.

21 Y. Li, K. Jiang, J. Feng, J. Liu, R. Huang, Z. Chen, J. Yang, Z. Dai, Y. Chen, N. Wang, W. Zhang, W. Zheng, G. Yang and X. Jiang, Adv. Healthcare Mater., 2017, 6, 1601343.

22 C. J. Malm, B. Risberg, A. Bodin, H. Bäckdahl, B. R. Johansson, P. Gatenholm and A. Jeppsson, Scand. Cardiovasc. J., 2012, 46, 57-62.

23 M. Scherner, S. Reutter, D. Klemm, A. Sterner-Kock, M. Guschlbauer, T. Richter, G. Langebartels, N. Madershahian, T. Wahlers and J. Wippermann, J. Surg. Res., 2014, 189, 340-347.

24 Y. Wan, C. Gao, M. Han, H. Liang, K. Ren, Y. Wang and H. Luo, Polym. Adv. Technol., 2011, 22, 2643-2648.

25 S. Zang, R. Zhang, H. Chen, Y. Lu, J. Zhou, X. Chang, G. Qiu, Z. Wu and G. Yang, Mater. Sci. Eng., C, 2015, 46, 111-117.

26 H. Luo, J. Dong, X. Xu, J. Wang, Z. Yang and Y. Wan, Composites, Part A, 2018, 109, 290-297.

27 H. Si, H. Luo, G. Xiong, Z. Yang, S. R. Raman, R. Guo and Y. Wan, Macromol. Rapid Commun., 2014, 35, 1706-1711.

28 Y. Wan, F. Zhang, C. Li, G. Xiong, Y. Zhu and H. Luo, J. Mater. Chem. A, 2015, 3, 24389-24396.

29 Z. Ming, S. Ma, K. Xu and P. K. Chu, Vacuum, 2015, 117, 73-80.

30 H. Luo, P. Xiong, J. Xie, Z. Yang, Y. Huang, J. Hu, Y. Wan and Y. Xu, Adv. Funct. Mater., 2018, 28, 1803075.

31 C. Tokoh, K. Takabe, M. Fujita and H. Saiki, Cellulose, 1998, 5, 249-261.

32 A. S. Ali, M. El-Aassar, F. Hashem and N. Moussa, Fibers Polym., 2019, 20, 2057-2069.

33 W. L. Shao, F. Sang, H. E. Shu jie, J. Y. Qian, L. I. Qiang and Q. Wang, J. Mater. Eng. Perform., 2016, 34, 535-539.

34 M. E. Uddin, R. K. Layek, H. Y. Kim, N. H. Kim, D. Hui and J. H. Lee, Composites, Part B, 2016, 90, 223-231.

35 H. Q. Liu and Y. L. Hsieh, J. Polym. Sci., Part B: Polym. Phys., 2002, 40, 2119-2129.

36 R. Kabiri and H. Namazi, Cellulose, 2014, 21, 3527-3539.

37 E. S. Sashina, G. Janowska, M. Zaborski and A. V. Vnuchkin, J. Therm. Anal. Calorim., 2007, 89, 887-891.

38 S.-M. Li, N. Jia, J.-F. Zhu, M.-G. Ma and R.-C. Sun, Carbohydr. Polym., 2010, 80, 270-275.

39 L. Ghasemi-Mobarakeh, M. P. Prabhakaran, M. Morshed, M.-H. Nasr-Esfahani and S. Ramakrishna, Biomaterials, 2008, 29, 4532-4539.

40 S. K. Norouzi and A. Shamloo, Mater. Sci. Eng., C, 2019, 94, 1067-1076.

41 Y. Xie, Y. Zheng, J. Fan, Y. Wang, L. Yue and N. Zhang, ACS Appl. Mater. Interfaces, 2018, 10, 22692-22702.

42 H. R. Baumgartner, Microvasc. Res., 1973, 5, 167-179.

43 H. Wang, Y. Feng, Z. Fang, W. Yuan and M. Khan, Mater. Sci. Eng., C, 2012, 32, 2306-2315.

44 C. Nie, L. Ma, C. Cheng, J. Deng and C. Zhao, Biomacromolecules, 2015, 16, 992-1001.
45 I.-G. Kang, C.-I. Park, Y.-J. Seong, H. Lee, H.-E. Kim and C.-M. Han, Mater. Sci. Eng., C, 2020, 106, 110287.

46 H. Jiang, X. Wang, C. Li, J. Li, F. Xu, C. Mao, W. Yang and J. Shen, Langmuir, 2011, 27, 11575-11581.

47 W. Elmay, E. Patoor, T. Gloriant, F. Prima and P. Laheurte, J. Mater. Eng. Perform., 2014, 23, 2471-2476.

48 D. Motlagh, J. Allen, R. Hoshi, J. Yang, K. Lui and G. Ameer, J. Biomed. Mater. Res., Part A, 2007, 82, 907-916.

49 L. Chen, H. He, M. Wang, X. Li and H. Yin, Tissue Eng. Regener. Med., 2017, 14, 359-370.

50 P. Xiang, S.-S. Wang, M. He, Y.-H. Han, Z.-H. Zhou, D.-L. Chen, M. Li and L. Q. Ma, Colloids Surf., B, 2018, 163, 19-28.

51 H.-F. Guo, W.-W. Dai, D.-H. Qian, Z.-X. Qin, Y. Lei, X.-Y. Hou and C. Wen, Acta Biomater., 2017, 54, 107-116.

52 H. Du, L. Tao, W. Wang, D. Liu, Q. Zhang, P. Sun, S. Yang and C. He, Mater. Sci. Eng., C, 2019, 100, 845-854.

53 B. Kinikoglu, J. C. Rodríguez-Cabello, O. Damour and V. Hasirci, J. Mater. Sci.: Mater. Med., 2011, 22, 1541-1554. 54 V. Beachley and X. Wen, Prog. Polym. Sci., 2010, 35, 868-892. 55 R. Krishnan, R. Rajeswari, J. Venugopal, S. Sundarrajan, R. Sridhar, M. Shayanti and S. Ramakrishna, J. Mater. Sci.: Mater. Med., 2012, 23, 1511-1519.

56 J. Gunn and M. Zhang, Trends Biotechnol., 2010, 28, 189-197. 57 D. Sankar, K. T. Shalumon, K. P. Chennazhi, D. Menon and R. Jayakumar, Tissue Eng., Part A, 2014, 20, 1689-1702.

58 T. J. Sill and H. A. von Recum, Biomaterials, 2008, 29, 1989-2006. 59 T. Lou, X. Wang and G. Song, Int. J. Biol. Macromol., 2013, 61, 353-358.

60 L. Cui, N. Zhang, W. Cui, P. Zhang and X. Chen, J. Bionic Eng., 2015, 12, 117-128.

61 L.-P. Yan, J. Silva-Correia, C. Correia, S. G. Caridade, E. M. Fernandes, R. A. Sousa, J. F. Mano, J. M. Oliveira, A. L. Oliveira and R. L. Reis, Nanomedicine, 2013, 8, 359-378.

62 X. Li, R. You, Z. Luo, G. Chen and M. Li, J. Mater. Chem. B, 2016, 4, 2903-2912.

63 X. Wang, B. Ding and B. Li, Mater. Today, 2013, 16, 229-241. 64 Y. Xu, W. Cui, Y. Zhang, P. Zhou, Y. Gu, X. Shen, B. Li and L. Chen, Adv. Healthcare Mater., 2017, 6, 1601457.

65 Y. Wan, T. Cui, Q. Zhang, Z. Yang, F. Yao and H. Luo, Macromol. Mater. Eng., 2018, 1800316.

66 F. Tian, H. Hosseinkhani, M. Hosseinkhani, A. Khademhosseini, Y. Yokoyama, G. G. Estrada and H. Kobayashi, J. Biomed. Mater. Res., Part A, 2008, 84, 291-299.

67 S. G. Kumbar, S. P. Nukavarapu, R. James, L. S. Nair and C. T. Laurencin, Biomaterials, 2008, 29, 4100-4107.

68 E. S. Fioretta, M. Simonet, A. I. Smits, F. P. Baaijens and C. V. Bouten, Biomacromolecules, 2014, 15, 821-829.

69 V. Milleret, T. Hefti, H. Hall, V. Vogel and D. Eberli, Acta Biomater., 2012, 8, 4349-4356.

70 I. K. Kwon, S. Kidoaki and T. Matsuda, Biomaterials, 2005, 26, 3929-3939.

71 Y. M. Ju, J. San Choi, A. Atala, J. J. Yoo and S. J. Lee, Biomaterials, 2010, 31, 4313-4321.

72 C. K. Hashi, Y. Zhu, G.-Y. Yang, W. L. Young, B. S. Hsiao, K. Wang, B. Chu and S. Li, Proc. Natl. Acad. Sci. U. S. A., 2007, 104, 11915-11920. 
73 J. R. Privratsky, C. M. Paddock, O. Florey, D. K. Newman, W. A. Muller and P. J. Newman, J. Cell Sci., 2011, 124, 1477-1485.

74 D. Baruch, C. Denis, C. Marteaux, D. Schoevaert, L. Coulombel and D. Meyer, Blood, 1991, 77, 519-527.

75 Y. Xie, M. Takano, D. Murakami, M. Yamamoto, K. Okamatsu, S. Inami, K. Seimiya, T. Ohba, Y. Seino and K. Mizuno, Am. J. Cardiol., 2008, 102, 27-31.
76 R. D. Frank, J. Weber, H. Dresbach, H. Thelen, C. Weiss and J. Floege, Kidney Int., 2001, 60, 1972-1981.

77 B. A. Hamedani, M. Navidbakhsh and H. A. Tafti, Biomed. Eng. Online, 2012, 11, 59-74.

78 R. G. Flemming, C. J. Murphy, G. A. Abrams, S. L. Goodman and P. F. Nealey, Biomaterials, 1999, 20, 573-588.

79 S. L. Goodman, P. A. Sims and R. M. Albrecht, Biomaterials, 1996, 17, 2087-2095. 